\title{
Intramyocellular lipid excess in the mitochondrial disorder MELAS
}

\section{MRS determination at $7 \mathrm{~T}$}

\section{OPEN}

Sailaja Golla, MD

Jimin Ren, $\mathrm{PhD}$

Craig R. Malloy, MD

Juan M. Pascual, MD, $\mathrm{PhD}$

Correspondence to

Dr. Pascual:

Juan.Pascual@UTSouthwestern. edu

\section{ABSTRACT}

Objective: There is a paucity of objective, quantifiable indicators of mitochondrial disease available for clinical and scientific investigation.

Methods: To this end, we explore intramyocellular lipid (IMCL) accumulation noninvasively by 7T magnetic resonance spectroscopy (MRS) as a reporter of metabolic dysfunction in MELAS (mitochondrial encephalomyopathy, lactic acidosis, and stroke-like episodes). We reasoned that mitochondrial dysfunction may impair muscle fat metabolism, resulting in lipid deposition (as is sometimes observed in biopsies), and that MRS is well suited to quantify these lipids.

Results: In 10 MELAS participants and relatives, IMCL abundance correlates with percent mitochondrial DNA mutation abundance and with disease severity.

Conclusions: These results indicate that IMCL accumulation is a novel potential disease hallmark in MELAS. Neurol Genet 2017;3:e160; doi: 10.1212/NXG.0000000000000160

\section{GLOSSARY}

ATP = adenosine triphosphate; IMCL = intramyocellular lipid; $\mathbf{M R S}=$ magnetic resonance spectroscopy; $\mathbf{m t D N A}=$ mitochondrial DNA; ppm = parts per million; TE $=$ echo time

Proper diagnosis and effective monitoring of patients with mitochondrial diseases remains a challenge in part because plasma and urine metabolite concentrations are nonspecific, tissue biopsies have limited acceptability and are prone to sampling error, and longitudinal measurements with invasive procedures are difficult. ${ }^{1}$

MELAS syndrome (mitochondrial encephalopathy, lactic acidosis, and stroke-like episodes) is a maternally inherited and relatively prevalent mitochondrial disorder. Multiple studies have reported magnetic resonance spectroscopy (MRS) findings in the brain including elevated lactate, but studies of metabolism in skeletal muscle by MRS methods have been limited. For example, a combined examination with ${ }^{31} \mathrm{P}$ and ${ }^{1} \mathrm{H}$ NMR spectroscopy has characterized mitochondrial function and intramyocellular lipids (IMCLs) in one individual with MELAS. ${ }^{2}$ This study points to the advantages of MRS in examinations of patients with suspected mitochondrial disorders — subject acceptability, safety, and detailed metabolic information specific to an organ.

The purpose of this study was to examine the feasibility of ${ }^{1} \mathrm{H}$ MRS at 7 Tesla (7T) in MELAS participants and maternal relatives. We separately determined normal IMCL in healthy controls; results were compared with an earlier cohort of healthy controls. In MELAS, a robust correlation was found between IMCL abundance and percent A3243G mutant mitochondrial DNA (mtDNA) abundance in the blood. The study was well tolerated by all participants. The high chemical shift dispersion at 7T was advantageous because the IMCL and other metabolite

\footnotetext{
From the Rare Brain Disorders Program (S.G., J.M.P.), Department of Neurology and Neurotherapeutics, Department of Pediatrics (S.G., J.M.P.), Advanced Imaging Research Center (J.R., C.R.M.), Department of Radiology (J.R., C.R.M.), Department of Internal Medicine (C.R.M.), Department of Physiology (J.M.P.), and Eugene McDermott Center for Human Growth \& Development/Center for Human Genetics (J.M.P.), The University of Texas Southwestern Medical Center, Dallas.

Funding information and disclosures are provided at the end of the article. Go to Neurology.org/ng for full disclosure forms. The Article Processing Charge was funded by the authors.

This is an open access article distributed under the terms of the Creative Commons Attribution-NonCommercial-NoDerivatives License 4.0 (CC BY-NC-ND), which permits downloading and sharing the work provided it is properly cited. The work cannot be changed in any way or used commercially without permission from the journal.
} 
signals were easily resolved. Thus, ${ }^{1} \mathrm{H}$ MRS at 7T may provide an avenue for investigating disease severity as well as the response of skeletal muscle to therapies.

METHODS Standard protocol approvals, registrations, and patient consents. This study was approved by the Institutional Review Board of the University of Texas Southwestern Medical Center. Informed written consent was obtained from all participants or their legal guardians as appropriate. They were studied over 4 months in one visit (each lasting less than 3 hours).

General methods. Mutant mtDNA abundance (expressed as percent of mutant DNA relative to total blood DNA) was routinely determined in the blood by quantitative PCR. Because mutation abundance can vary with age by $0.6 \%-1.9 \%$ per year in each person, participants were genotyped within 3 years preceding enrollment. All participants' symptoms and medical history were obtained using a standardized questionnaire. Complete hematologic, endocrine, chemical, and lipid profiles (including blood cell count, blood electrolytes, transaminases, lactate, urea nitrogen, creatinine, amino acids, creatine kinase, free fatty acids, thyroid-stimulating hormone, T4, lipid panel [total, low-density lipoprotein and high-density lipoprotein cholesterol, and triglycerides], fasting blood glucose, and hemoglobin A1c [HbAlc]) were measured by standard clinical laboratory methods and compared with normal values established in each laboratory.

Skeletal muscle proton MRS. The details of the examination have been published. Briefly, leg calf muscles of rested ( $>2$ hours) participants were subject to MRS in a 7T system (Achieva; Philips Medical Systems, Cleveland, $\mathrm{OH}$ ) without sedation. Scan sessions lasted less than 1 hour. Participants were positioned supine with their legs parallel to the magnetic field and the left calf sitting on the center of a partial volume quadrature transmit/ receive coil customized to fit the shape of a human calf. Axial, coronal, and turbo spin-echo images were first acquired to guide voxel placement within the soleus muscle. Single-voxel ${ }^{1} \mathrm{H}$ MRS spectra were collected from the soleus with a volume of 3-5 mL, using a STimulated Echo Acquisition Mode (STEAM) sequence, at long echo time (TE) of both 140 and 280 milliseconds, and a constant repetition time of 2 seconds. A typical number of scans were 192 (or 6.4 minutes for TE 140 milliseconds) and 256 (or 8.5 minutes for TE 280 milliseconds). No water suppression pulses were applied during data acquisition to avoid signal reduction due to possible magnetization-transfer effects on metabolites as we previously described. ${ }^{3}$ The ${ }^{1} \mathrm{H}$ chemical shifts of all metabolite resonances arising from muscle were referenced to creatine methyl protons set to 3.02 parts per million (ppm) (Cr3). The area of each metabolite ${ }^{1} \mathrm{H}$ resonance signal was determined by fitting the spectrum to a Voigt lineshape (variable proportions of lorentzian plus gaussian) using ACD software (Advanced Chemistry Development, Inc., Toronto, ON, Canada). The asymmetry of the extramyocellular lipid signal was fitted by 2 Voigt lineshapes as described. ${ }^{3}$ For quantitative comparison between the metabolites, the area of creatine methyl ${ }^{1} \mathrm{H}$ resonance signal $(\mathrm{Cr} 3)$ was used as the internal standard $(30 \mathrm{mmol} / \mathrm{kg}$ wet tissue weight). All MRS data quantifications are expressed in millimoles per kilogram wet tissue weight. Errors denote mean \pm SD where indicated.

RESULTS All the participants tested positive for the m.3243A $>\mathrm{G}$ mutation except those identified as maternal relatives (table). As a group, the MELAS participants exhibited the common features of the disorder such as lactic acidosis, stroke-like episodes, hearing loss, neuropathy and, in some, diabetes as indicated in the table. Elevated IMCLs were observed in all the MELAS participants examined by MRS (figure 1). Of the 8 participants with MELAS (table), the average concentration of IMCLs was $26 \pm 18$ $\mathrm{mmol} / \mathrm{kg}$ muscle mass. The average concentration of IMCL among participants with the more severe phenotype (participants 4, 7, 8, and 10) tended to be higher, $33 \mathrm{mmol} / \mathrm{kg}$ muscle mass. The association between IMCL abundance and percent mutant mtDNA abundance depended on the coexistence of diabetes (figure 2).

The ratio of the trimethylamine signal from carnitine at $3.20 \mathrm{ppm}$ relative to the creatine methyl signal at $3.02 \mathrm{ppm}$ (carnitine/Cr3) is typically $<1$ or $\sim 1$;

\begin{tabular}{|c|c|c|c|c|c|c|}
\hline \multicolumn{7}{|c|}{ Table Characteristics of the participants and IMCL values } \\
\hline Participant & Age, y & Sex & Diabetes & MELAS findings & $\begin{array}{l}\text { m.A3243G } \\
\text { abundance, \% }\end{array}$ & $\begin{array}{l}\text { IMCL, } \mathrm{mmol} / \mathrm{kg} \\
\text { wet weight }\end{array}$ \\
\hline 1 & 27 & $\mathrm{~F}$ & No & None, maternal relative & 0 & 7.2 \\
\hline 2 & 52 & $\mathrm{~F}$ & No & Elevated blood lactate & 19 & 7.0 \\
\hline 3 & 25 & $\mathrm{~F}$ & No & Deafness & 44 & 12.9 \\
\hline 4 & 16 & $\mathrm{~F}$ & No & Elevated blood lactate and migraine & 50 & 10.6 \\
\hline 5 & 18 & M & No & Elevated blood lactate, cerebral infarction, and dementia & 71 & 18.4 \\
\hline 6 & 39 & $\mathrm{~F}$ & Yes & None, maternal relative & 0 & 19.6 \\
\hline 7 & 47 & $\mathrm{~F}$ & Yes & Elevated blood lactate and distal neuropathy & 0 & 23 \\
\hline 8 & 43 & $\mathrm{~F}$ & Yes & Elevated blood lactate, migraine, and short stature & 20 & 40.3 \\
\hline 9 & 26 & $\mathrm{~F}$ & Yes & Elevated blood lactate and distal neuropathy & 25 & 37.5 \\
\hline 10 & 26 & M & Yes & Elevated blood lactate, deafness, upgaze palsy, and cerebral infarction & 25 & 58.8 \\
\hline
\end{tabular}

Abbreviation: IMCL = intramyocellular lipid. 


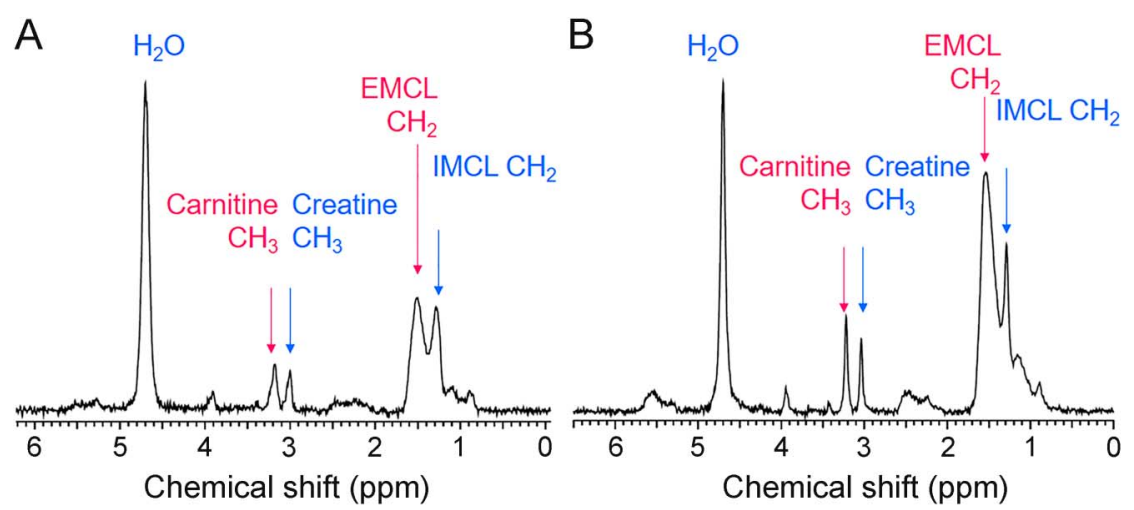

MRS of 2 soleus muscles (participants $1[A]$ and $2[B]$ ). Proton spectra were acquired at 2 echo times as described in the text. Solid black lines are plots of the spectra. IMCL $\mathrm{CH} 2$ represents resonances attributed to intramyocellular lipids, whereas EMCL $\mathrm{CH} 2$ is considered to arise from extramyocellular lipids. Carnitine $\mathrm{CH} 3=$ signal arising from carnitine; creatine $\mathrm{CH} 3$ = signal emanating from carbon 3 of creatine; $\mathrm{H} 2 \mathrm{O}$ = water spectrum; MRS = magnetic resonance spectroscopy; ppm $=$ parts per million.

the relative signals are sensitive to acquisition conditions. With a TE of 140 milliseconds, the signals are typically $\sim 1: 1$ or nearly equally sized "twin peaks." MELAS participants displayed significantly higher trimethylamine/Cr3 ratio $(1.46 \pm 0.40)$.

The relation between IMCL and plasma lactate, urea nitrogen, creatinine, free fatty acids, triglycerides, and total cholesterol was also examined. No significant correlation was found.

DISCUSSION There is a paucity of biomarkers and of noninvasive methods available for the study of mitochondrial disorders. These obstacles limit clinical trials. For example, our study of dichloroacetate (a lactate-reducing drug) in a mitochondrial disorder was discontinued when toxic neuropathy was detected by nerve conduction monitoring despite the appearance of subjective benefits such as increased physical endurance. A key limitation is the difficulty of acquiring objective measurements of metabolic efficacy in the target tissue. ${ }^{4}$

Our study demonstrated an increase in the concentration of IMCLs among participants with MELAS syndrome compared with historical healthy controls. A simple explanation is that skeletal mitochondrial function in MELAS is substantially impaired, resulting in diminished oxidation of fatty acids and accumulation of IMCL in the cytosol. ${ }^{5}$ Among the cytoplasmic lipids that accumulate in relation to metabolic dysfunction are diacylglycerol and ceramide. Extensive evidence links these lipids with human mitochondrial dysfunction and with

Figure $2 \quad I M C L$, mtDNA, and diabetes correlations
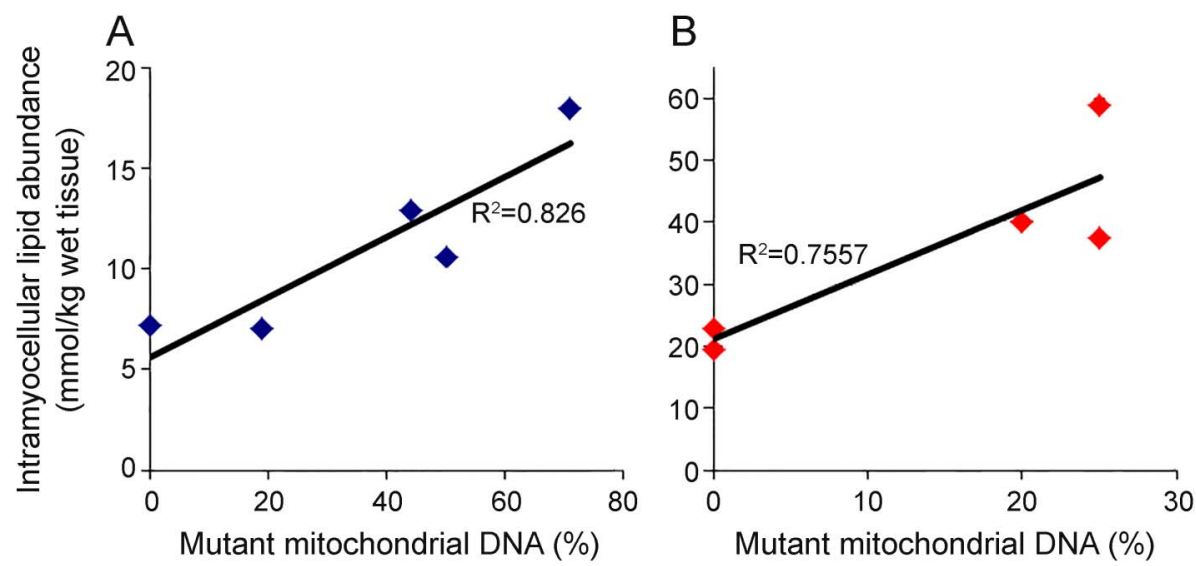

IMCL abundance correlations with percent mutant mtDNA (m.A3243G) in the blood. (A) Correlations for nondiabetic (i.e., $\mathrm{HbA} 1 \mathrm{c}<6 \%$ and no history of diabetes) participants. (B) Correlations for diabetic participants ( $\mathrm{HbA} 1 \mathrm{c}>6 \%$ and a history of diabetes). Correlation coefficients with a straight line are given in each panel. IMCL = intramyocellular lipid; mtDNA, mitochondrial DNA. 
mitochondrial-related insulin resistance. For example, in diabetes, slowed postexercise mitochondrial adenosine triphosphate (ATP) resynthesis is related to increased insulin resistance, ${ }^{6}$ whereas insulinstimulated rates of mitochondrial ATP synthesis are reduced in otherwise healthy insulin-resistant participants. ${ }^{7}$ Accumulation of these lipids has also been observed by MRS in relation to insulin resistance in otherwise healthy ${ }^{8,9}$ and diabetic participants. An earlier case report did not find a significant increase in IMCL in a single participant using skeletal water as an internal reference and a TE of 30 milliseconds. ${ }^{2}$ This study used relatively long echo times to suppress water signal, so differences in acquisition and quantitation methods may be important.

This study found an unexpected increase in the carnitine/creatine ratio. Because this MRS method only detects the ratio of NMR-visible metabolites and not absolute concentration, this altered ratio could be due to some combination of altered relaxation times, increased carnitine, decrease creatine, or some combination of these factors. Further studies will clarify any potential racial differences in IMCL abundance in relation to insulin resistance ${ }^{10}$ in MELAS and the presence of IMCL in other mitochondrial diseases.

\section{AUTHOR CONTRIBUTIONS}

Conception and design of the study: J.M.P. and C.R.M. Acquisition and analysis of data: S.G., J.R., C.R.M., and J.M.P. Drafting of the manuscript: S.G., J.R., C.R.M. and J.M.P. Drafting of the figures: S.G., J. R., C.R.M., and J.M.P.

\section{STUDY FUNDING}

This work was supported by a pilot grant to J.M.P. and C.R.M. under NIH grant UL1TR001105 and by a gift of the Hegi Foundation to Children's Medical Center Dallas to support the work of S.G. and J. M.P. J.M.P. and C.R.M. are also supported by NIH grants NS077015, NS078059, EB015908, and RR024982.

\section{DISCLOSURE}

Dr. Golla reports no disclosures. Dr. Ren has served on the editorial boards of the Journal of Analytical \& Molecular Techniques, BioMed Research International, and Current Metabolomics. Dr. Malloy has served on the editorial board of Tomography and has received publishing royalties for writing occasional book chapters $(<\$ 100)$. Dr. Pascual has served on the editorial board of Neuroscience Letters and has received research support from NIH/ National Institute of Neurological Disorders and Stroke and NIH/NIMH. Go to Neurology.org/ng for full disclosure forms.

Received March 6, 2017. Accepted in final form April 7, 2017.

\section{REFERENCES}

1. DiMauro S, Paradas C. Mitochondrial disorders due to mutations in the mitochondrial genome. In: Rosenberg RN, Pascual JM, editors. Rosenberg's Molecular and Genetic Basis of Neurological and Psychiatric Disease, 5th ed. San Diego: Academic Press; 2015.

2. Szendroedi J, Schmid AI, Meyerspeer M, et al. Impaired mitochondrial function and insulin resistance of skeletal muscle in mitochondrial diabetes. Diabetes Care 2009;32: 677-679.

3. Ren J, Sherry AD, Malloy CR. 1H MRS of intramyocellular lipids in soleus muscle at $7 \mathrm{~T}$ : spectral simplification by using long echo times without water suppression. Magn Reson Med 2010;64:662-671.

4. Kaufmann P, Engelstad K, Wei Y, et al. Dichloroacetate causes toxic neuropathy in MELAS: a randomized, controlled clinical trial. Neurology 2006;66:324-330.

5. Kiens B. Skeletal muscle lipid metabolism in exercise and insulin resistance. Physiol Rev 2006;86:205-243.

6. Cree-Green M, Newcomer BR, Brown MS, et al. Delayed skeletal muscle mitochondrial ADP recovery in youth with type 1 diabetes relates to muscle insulin resistance. Diabetes 2015;64:383-392.

7. Petersen KF, Dufour S, Shulman GI. Decreased insulinstimulated ATP synthesis and phosphate transport in muscle of insulin-resistant offspring of type 2 diabetic parents. PLoS Med 2005;2:e233.

8. Sinha R, Dufour S, Petersen KF, et al. Assessment of skeletal muscle triglyceride content by (1)H nuclear magnetic resonance spectroscopy in lean and obese adolescents: relationships to insulin sensitivity, total body fat, and central adiposity. Diabetes 2002;51:1022-1027.

9. Goodpaster BH, Thaete FL, Simoneau JA, Kelley DE. Subcutaneous abdominal fat and thigh muscle composition predict insulin sensitivity independently of visceral fat. Diabetes 1997;46:1579-1585.

10. Misra A, Sinha S, Kumar M, Jagannathan NR, Pandey RM. Proton magnetic resonance spectroscopy study of soleus muscle in non-obese healthy and type 2 diabetic Asian Northern Indian males: high intramyocellular lipid content correlates with excess body fat and abdominal obesity. Diabet Med 2003;20:361-367. 


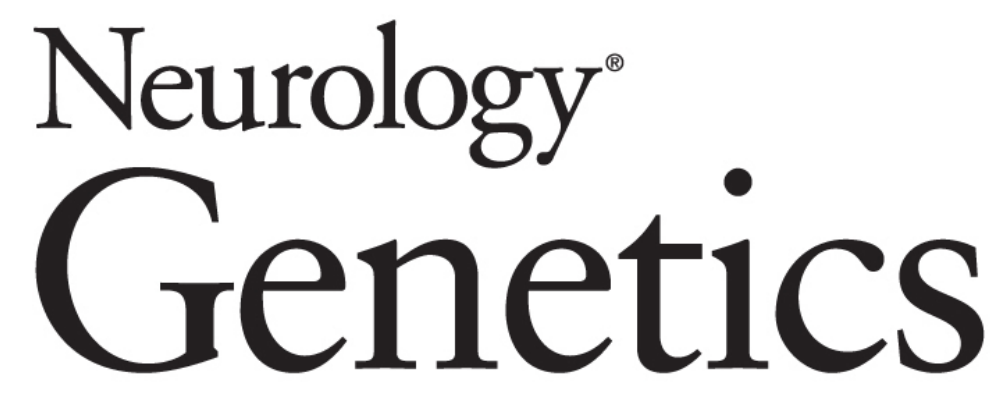

Intramyocellular lipid excess in the mitochondrial disorder MELAS: MRS determination at $7 \mathrm{~T}$

Sailaja Golla, Jimin Ren, Craig R. Malloy, et al. Neurol Genet 2017;3;

DOI 10.1212/NXG.0000000000000160

This information is current as of May 25, 2017

Neurol Genet is an official journal of the American Academy of Neurology. Published since April 2015, it is an open-access, online-only, continuous publication journal. Copyright Copyright ( 2017 The Author(s). Published by Wolters Kluwer Health, Inc. on behalf of the American Academy of Neurology.. All rights reserved. Online ISSN: 2376-7839.

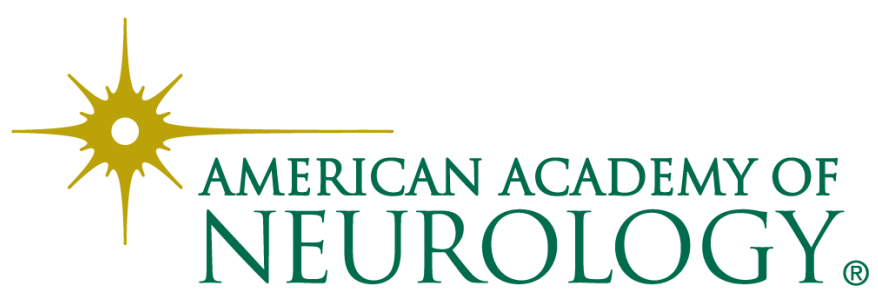




\section{Updated Information \& Services}

References

Citations

Subspecialty Collections

Permissions \& Licensing

Reprints including high resolution figures, can be found at: http://ng.neurology.org/content/3/3/e160.full.html

This article cites 9 articles, 4 of which you can access for free at: http://ng.neurology.org/content/3/3/e160.full.html\#\#ref-list-1

This article has been cited by 3 HighWire-hosted articles: http://ng.neurology.org/content/3/3/e160.full.html\#\#otherarticles

This article, along with others on similar topics, appears in the following collection(s):

Metabolic disease (inherited)

http://ng.neurology.org//cgi/collection/metabolic_disease_inherited Mitochondrial disorders

http://ng.neurology.org//cgi/collection/mitochondrial_disorders

Mitochondrial disorders; see Genetics/Mitochondrial disorders http://ng.neurology.org//cgi/collection/mitochondrial_disorders_see_ge netics-mitochondrial_disorders

\section{MRS}

http://ng.neurology.org//cgi/collection/mrs

Muscle disease

http://ng.neurology.org//cgi/collection/muscle_disease

Information about reproducing this article in parts (figures,tables) or in its entirety can be found online at:

http://ng.neurology.org/misc/about.xhtml\#permissions

Information about ordering reprints can be found online: http://ng.neurology.org/misc/addir.xhtml\#reprintsus

Neurol Genet is an official journal of the American Academy of Neurology. Published since April 2015, it is an open-access, online-only, continuous publication journal. Copyright Copyright $\odot 2017$ The Author(s). Published by Wolters Kluwer Health, Inc. on behalf of the American Academy of Neurology.. All rights reserved. Online ISSN: 2376-7839.

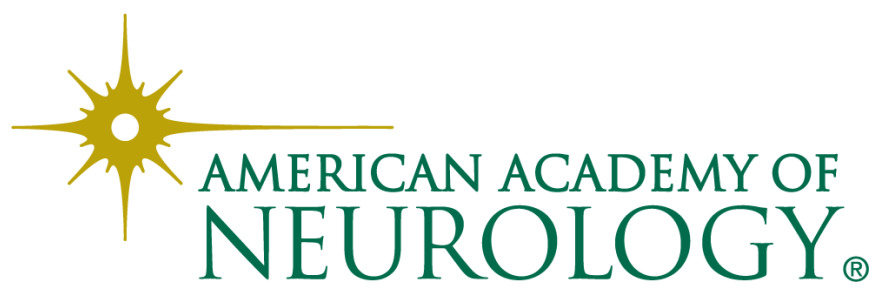

